\title{
RICHARD STALLMAN, SOFTWARE LIBRE Y LICENCIA GNU: ÉTICA, INTELIGENCIA Y COMUNIDAD
}

\section{RICHARD STALLMAN, FREE SOFTWARE AND GNU: ETHICS, INTELLIGENCE COMMUNITY}

\section{AUTORES}

Reynaldo Cordero Corro: Programador informático de la Universidad de Alcalá de Henares (España) y activista contra la ley del canon digital. Delegado sindical de CSIT-UP. Articulista habitual en foros sobre los derechos de copia y de autoría. reynaldo.cordero@uah.es

\section{CURRÍCULUM VITAE}

Programador informático de la Universidad de Alcalá de Henares (España) y activista contra la ley del canon digital. Delegado sindical de CSIT-UP. Articulista habitual en foros sobre los derechos de copia y de autoría.

\section{RESUMEN}

Como colofón al III congreso Hispalinux, el día 12 de noviembre, en el campus de Leganés de la universidad Carlos III de Madrid, se celebró la extraordinaria conferencia El movimiento de software libre y el desarrollo del sistema operativo libre GNU/Linux a cargo de Richard Stallman, conocido como RMS, a la sazón el creador y más importante impulsor de ambas realidades. 


\section{PALABRAS CLAVE}

Software libre - GNU - Richard Stallman

\section{ABSTRACT}

As a climax to the Third Congress Hispalinux, on 12 November at the Leganes campus of the University Carlos III of Madrid, was held the extraordinary conference of free software movement and development of the free operating system GNU / Linux by Richard Stallman, known as RMS, at that time the most important creator and promoter of both realities.

\section{KEY WORDS}

Free Software - GNU - Richard Stallman

Como colofón al III congreso Hispalinux, el día 12 de noviembre, en el campus de Leganés de la universidad Carlos III de Madrid, se celebró la extraordinaria conferencia "El movimiento de software libre y el desarrollo del sistema operativo libre GNU/Linux" a cargo de Richard Stallman, conocido como "RMS", a la sazón el creador y más importante impulsor de ambas realidades.

Nos sorprendió su empeño en dar la conferencia en español, que le cuesta bastante, pero esto no le impidió ser preciso, claro y elegante las dos horas largas que habló. 
Quisiera aclarar que soy programador informático asalariado, pero no periodista profesional. Trataré de centrarme en algunos aspectos de la charla tal y como los entendí.

Stallman formaba parte de un equipo que compartía el código fuente (secuencia de instrucciones escritas a mano) de los programas, que es algo natural, necesario y evidente para cualquier equipo de desarrollo. Incluso esto es así para con otros programadores interesados, ajenos a nuestro grupo ¿por qué negarse a ayudar a un colega en algo tan razonable como compartir código fuente?

Pero un mal día se encontró con que ALGUIEN había encontrado la manera de dinamitar esto. Como en las mejores novelas de terror, su equipo recibió un regalo. Una fascinante y revolucionaria impresora. El colmo para alguien enamorado de su trabajo como programador avanzado ¿El código fuente o las especificaciones para "sacarle partido"? ¡No estaban! No puede ser. Debía haber un error... Mientras tanto, se empezó a utilizar tal y como venía, esto es, utilizando el programa de interfaz con la impresora que no podían modificar.

Un detalle tan tonto como que el software propietario entregado no avisaba de los atascos de papel provocó innumerables problemas, ya que si uno enviaba algo valioso a la impresora tenía que interrumpir el trabajo y darse un paseo hasta la impresora para comprobar que efectivamente se había impreso. La ley de Murphy se encargó de aquellos que no eran tan precavidos. Al poco tiempo la fascinante y revolucionaria impresora había provocado tal cantidad de pérdidas de tiempo y de esfuerzos que los usuarios (es decir, las víctimas de este software propietario) se sentían profundamente frustrados.

El software propietario está avalado por unos contratos que son abusivos, injustos y malvados ya que atacan una serie de libertades irrenunciables acerca del uso de los 
programas de ordenador (esas "licencias" están diseñadas para quitar algunos o todos de los legítimos derechos que se deberían tener como usuario, que se resumen en que de verdad te sea útil y no te cause perjuicios por utilizarlo de una forma razonable, lo que en el caso de los programas de ordenador supone la necesidad de poder compartirlos y mejorarlos). Entrar en el juego del software propietario como usuario y, especialmente, como cómplice-desarrollador es una gran desgracia.

Richard Stallman es un gran líder moral al tomar la decisión de enfrentarse a las licencias software propietario. Alguien admirable al que merece la pena conocer.

...así comienza un artículo escrito por Reynaldo Cordero, enviado especial de Vivat Academia para cubrir este reportaje...

Este escrito se acoge a la licencia LGPL. (Continuará)

Los riesgos de los móviles para la salud, a la espera de veredicto

Diario "El País", Barcelona (28-11-00)

La controvertida cuestión de los riesgos que los teléfonos móviles representan para la salud es sometida a análisis en dos trabajos publicados en el último número de la revista médica The Lancet, concluyendo que todavía es pronto para emitir un veredicto.

Desde una perspectiva epidemiológica, Kenneth Rothman, de Epidemiology Resources de Boston (EE UU), llega a la conclusión de que es demasiado pronto para emitir un juicio científico sobre los riesgos que conllevan para la salud los teléfonos 
móviles. "Según los indicios epidemiológicos de que disponemos en la actualidad, el principal riesgo para la salud pública es claramente la colisión de vehículos, una consecuencia de la conducta más que de la exposición a la radiofrecuencia como tal".

"Ninguno de los diversos estudios sobre exposición ocupacional a las radiofrecuencias y los pocos disponibles sobre usuarios de teléfonos móviles ofrecen indicios claros de que exista una asociación con los tumores cerebrales u otras enfermedades. Incluso aunque los estudios que se están realizando encontrasen grandes efectos relativos sobre el cáncer cerebral, el aumento absoluto del riesgo sería probablemente mucho menor que el riesgo derivado de las colisiones de vehículos de motor", comenta.

Efectos no térmicos

Por otro lado, Gerard Hyland, de la Universidad de Warwick (Reino Unido) y el Instituto Internacional de Biofísica Neuss-Holzheim, de Alemania, sugiere que el uso de teléfonos móviles puede producir sutiles efectos no térmicos, asociados principalmente con una sinergia o resonancia entre las frecuencias generadas por diferentes elementos de la tecnología de los teléfonos móviles y las frecuencias naturales del organismo. "Si estas influencias conllevan consecuencias adversas para la salud, las actuales directrices serían inadecuadas", afirma.

"A pesar de la incertidumbre sobre si las influencias no térmicas de las que se ha informado afectan negativamente a la salud, existe una relación entre algunos de estos efectos y los problemas neurológicos de los que se han quejado algunos usuarios de teléfonos móviles y personas expuestas durante mucho tiempo a la radiación de la estación base. Éstos deberían ser indicadores para la futura investigación", afirma. En un comentario adjunto, Philip Dendy, ex médico jefe del Addenbrookes Hospital de Cambridge (Reino Unido), comenta que sería difícil 
establecer unos límites más rigurosos para la regulación de los teléfonos móviles. "En última instancia, la percepción de seguridad de los usuarios estará fuertemente influida por el beneficio que les reporte la actividad en cuestión. Este nivel es claramente elevado en el caso de los teléfonos móviles".

\section{VERSIÓN 1.5 (CON CAMBIOS IMPORTANTES)}

Como colofón al III congreso Hispalinux, el día 12 de noviembre, en el campus de Leganés de la universidad Carlos III de Madrid, se celebró la conferencia "El movimiento de software libre y el desarrollo del sistema operativo libre GNU/Linux" nada menos que por Richard Stallman (RMS), el artífice y gran impulsor de los mismos.

Nos impresionó su empeño en dar la conferencia en español, ya que le cuesta bastante, pero dejó claro que no da conferencias para sacarse unos cuartos o para que la gente sepa lo listo y lo importante que es: su principal motivación es evangelizar con la verdad del software libre, por lo que era importante una comunicación directa y estrecha, y eso justificaba tal esfuerzo.

La claridad, la precisión y la elegancia con la que se expresa son dignas de mención, como cuando desnuda moralmente a aquellos que firman contratos laborales en los que se comprometen a "no ayudar a los demás", incluso si el culpable del daño son ellos mismos.

Todos los programadores profesionales de software propietario han aceptado dicha cláusula, que se resume en la obligación de "no revelar el código fuente (secuencia de instrucciones escritas a mano) a terceros". Esto convierte a los que utilizan dichos programas, literalmente, en prisioneros del mismo. 
Habitualmente las víctimas se verán obligadas a realizar farragosas e insatisfactorias chapuzas con el fin de que el programa les funcione de forma aceptable. Y a rezar para que una nueva versión del programa no arruine sus trucos de fortuna...

Stallman nos contó que tomó conciencia del problema cuando era un privilegiado programador en el prestigioso MIT, allá por los 80 , y formaba parte de un equipo que compartía, como algo natural, necesario y evidente, el código fuente de los programas, incluso que éste se compartía con otros programadores interesados, ajenos a su grupo. No eran una excepción. Era lo lógico. ¿Por qué negarse a ayudar a un colega en algo tan razonable como compartir código fuente?

Pero llegó la pesadilla. Como en las mejores novelas de terror, su equipo recibió un regalo maquiavélico: una fascinante y revolucionaria impresora -nada menos que una de las primeras impresoras láser- que hacía unas hermosas "líneas perfectas", en palabras de Richard. Todos en su equipo estaban deseando utilizarla con sus programas, sacarle todo el partido que esa fastuosa máquina prometía ofrecerles. Fue entonces cuando descubrieron que esa impresora era distinta a las demás en otra cosa... en vez de venir documentadas las especificaciones de la máquina y de incluir el código fuente del programa controlador de la misma, sólo se incluía el programa controlador listo para usar pero imposible de estudiar o modificar... Debía haber un error... o eso fue lo que pensaron.

Mientras tanto, se empezó a utilizar tal y como venía, esto es, utilizando el programa que controlaba la impresora y que no podían modificar.

Como era absolutamente previsible (esto es, siguiendo con los clichés de un guión de terror), empezaron a aparecer diversos problemas que bajo una apariencia menor escondían auténtico veneno. Un defecto tan tonto como que el software propietario 
entregado no avisaba de los atascos de papel provocó innumerables contratiempos: si uno enviaba algo especialmente valioso a la impresora tenía que interrumpir el trabajo y darse un paseo hasta la misma para comprobar que efectivamente se había impreso. La ley de Murphy, por otra parte, convirtió en "muy valiosos" algunos documentos que inicialmente no lo eran y que se perdieron para siempre. Al poco tiempo la fascinante y revolucionaria impresora había provocado tal cantidad de pérdidas de tiempo y de esfuerzos que los usuarios (es decir, las víctimas de este software propietario) se sentían profundamente frustrados.

RMS consiguió hablar con el programador del controlador de impresora que les estaba causando los trastornos y cuando éste le informó de que "por contrato" no podía hacer nada para ayudarle, se dio cuenta del significado de semejante actitud: la manera natural, lógica y razonable de entender la programación de ordenadores era terriblemente vulnerable y por lo tanto desaparecería. Su grupo desaparecería.

La película de terror llega a su punto culminante: ya todo está perdido, la estupidez ha triunfado, sólo queda firmar y convertirse en un zombi más..."O morir de hambre".

Un resumen de lo que pasó a continuación es que decidió resistir: una vez estudiado el problema, creó un sistema operativo portable -que pudiera ser utilizado sobre muchas arquitecturas y modelos de ordenadores- inspirado en el UNIX, para hacerlo sencillo de aprender y que llamó GNU (como acrónimo recursivo de GNU No es Unix) y que protegió con un nuevo tipo de licencia de software que garantizaba unas libertades básicas a los usuarios: la licencia GNU.

El software propietario está avalado por unos contratos que son abusivos, injustos y malvados ya que atacan una serie de libertades irrenunciables acerca del uso de los programas de ordenador (esas "licencias" están diseñadas para quitar algunos o 
todos de los legítimos derechos que se deberían tener como usuario, que se resumen en que de verdad te sea útil y no te cause perjuicios por utilizarlo de una forma razonable, lo que en el caso de los programas de ordenador supone la necesidad de poder compartirlos y mejorarlos). La licencia GNU, por el contrario, garantiza las libertades mencionadas y, en la práctica, se demuestra que tanto las empresas como los propios programadores pueden utilizarlas para sus programas sin que ello dañe sus legítimos intereses.

Richard Stallman se convirtió en un gran líder moral al tomar la decisión de enfrentarse a las licencias software propietario. Alguien admirable al que merece la pena conocer. Al que merece la pena seguir.

...así comienza un artículo redactado-coordinado por Reynaldo Cordero, programador profesional y enviado especial de Vivat Academia para cubrir este reportaje, que pretende ir completando, gracias a las ayudas de los lectores. Este documento va por la versión 1.5 y el plan previsto es que se recojan para el número de marzo las contribuciones finales de este trozo, y se presente el siguiente "capítulo" que se ha preferido no publicar por ahora, para tratar de afianzar esta introducción.

El autor ha acordado con aquellos que han colaborado hasta el momento, que cuando se dé por finalizado el artículo, se publicarán los créditos.

Este escrito se acoge a la licencia LGPL.

La parte invariable acordada es: "Publicado originariamente en www.VivatAcademia.org"

(Continuará) 
PD: Se sigue invitando a los lectores a participar en este proyecto. Cualquier sugerencia y/o crítica será bienvenida. Gracias de antemano. 